International Journal of Engineering \& Technology, 7 (4.38) (2018) 330-334
International Journal of Engineering \& Technology
SPC
Website $:$ www.sciencepubco.com/index.php/IJET
Research paper

\title{
Studying the Nature of Human Factor and Developing the Method of Solving the Problem
}

\author{
Marin L. Marinov ${ }^{1 *}$, Igor' Vasil'evich Osipchuk², Elena Aleksandrovna Malygina² \\ ${ }^{1}$ Solomenko Institute of Transport Problems of the Russian Academy of Sciences, V.O. 12 line, 13, St. Petersburg, 199178, Russia \\ ${ }^{2}$ Saint-Petersburg University of State Fire Service of Emercom of Russia, Moskovskiy prospect, 149, Saint-Petersburg, 196105, Russia \\ *Corresponding author E-mail: marinov.l.m@mail.ru
}

\begin{abstract}
The studies of human influence on the effectiveness of professional activity should consider that the concept of "human factor" is too general, and it is impossible to use it for an objective evaluation of human's professional activity. The most powerful and robust factors of human behavior, such as virtue, will and interest, are not considered enough in the studies of the influence of the human factor on the individual's professional activity.

The research results presented in the article change the existing opinion that the only way to increase the effectiveness of professional activity is to increase the effort to select people with the necessary qualities, skills and high level of professional and psychological training. Such effort to optimize the secondary factors, and ignorance towards the effect of the key behavioral factors (virtue - will - interest), are the fundamental errors and the reasons of the low work effectiveness.
\end{abstract}

Keywords: Effectiveness; Human factor; Modelling, Professional activity; Psychological training.

\section{Introduction}

Current stage of scientific, technological, social and economic development is accompanied by the increased role of people in the structure of the national wealth, which requires a more complete consideration of physical, mental, moral and social needs of people and an increase in quality of human potential of the nation.

The concept of "human factor" is widely used in the modern science $[1,2,3 ; 4]$.

The discussions about the human factor typically point out that a human affects the safety of any process and the success of his activity by his behavior; but how does that happen? There are different approaches to studying the influence of human factor on the safety and success of the conducted professional activity. However, the majority of them lead to the creation of large and complex systems of criteria for expert evaluation that might often be impossible to use. At this point, it is only clear that a human has a leading role at all stages of activity, and, regardless of the fact that he is not the only source of errors, it is him who is the element that unites all previous actions by his decision. A human per se is the defining factor in the occurring critical situations and the last segment in the process of their development until the state of emergency. Practical experience shows that a human affects both the state of the technical objects (quality of design and production) and the security of their use. A human either evaluates, or predefines all of the conditions of the conducted activity. He also defines the level of additionally conducted security events - predicting the expected threats, monitoring the conditions, analyzing the situations and actions for providing safety. At the same time, it is possible to minimize the negative effect of the human factor in the occurrence of anthropogenic and social emergencies [5].
Considering all of the aspects of the human factor concept, it becomes clear that only human behavior, which is based on the constantly repeating process of decision making, corresponds to its meaning.

Current studies of human behavior include such fields as studies of team psychology and culture of safety; creation of a matrix of individual traits; diagnostics of cognitive skills; testing of individual's personality traits; studies of separate temperamental characteristics; definition of human needs, etc. The most important trait of the results of a human behavior study is the fact that almost none of them point out the factors that could be a constant adjustment for evaluating and predicting human behavior in various situations. In order to describe the influence of constantly acting behavioral factors, it is necessary to create a unified model that would contain such heterogeneous categories as instinct, perception, feelings, wisdom, intelligence, personality, spirituality, intuition, imagination, idea, thought, virtue and interest. Currently, the nature of these categories has not been studied enough. Regardless of this, and based on the knowledge of their functional role and purpose, as well as the present information about their interaction and dynamics, they can be united in a single model.

The presented model of the psychological processes' dynamics points to the following sequence: the image of an observed object or a phenomenon from the external world is perceived by the sensory organs and reflected in the human mind, therefore creating certain sensations, feelings and emotions or evoking certain instincts (Fig. 1). 


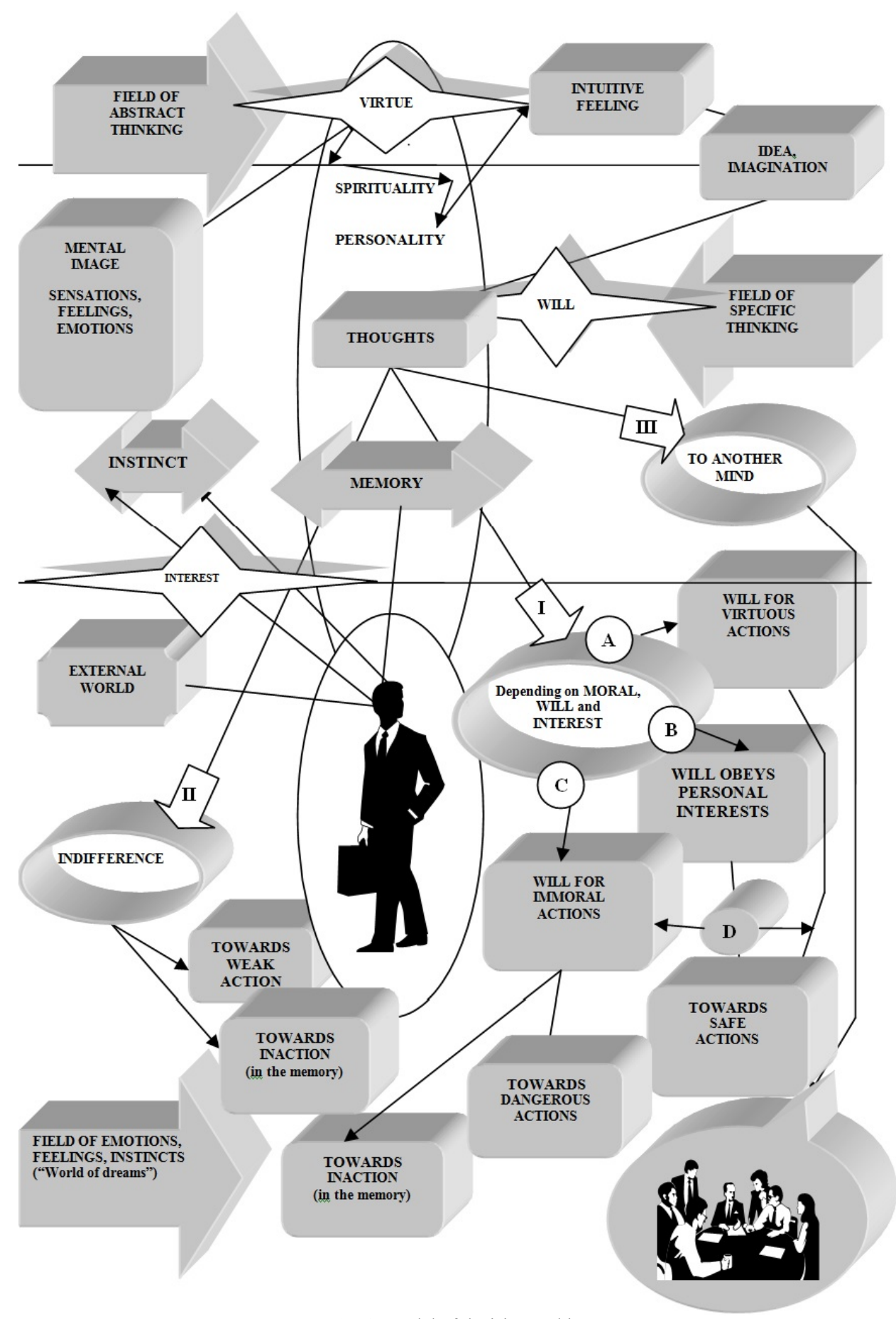

Fig. 1. Model of decision making

The same effect also occurs as a result of randomly appearing thought, feeling or association that provoke some initial interest towards certain objects or phenomena that a person has seen before. A mental image (a conscious thought) leads to the occurrence of an idea that can further manifest as intuitive perception, or it can be specified by the human mind, therefore transforming into a developing thought. In accordance with the person's will, the mind can "design" a thought in one of the following directions: the thought can evoke the feeling of increased interest towards the given object and become the reason for further actions (Fig. 1, I); the thought can evoke the feeling of indifference (Fig. 1, II); the thought can affect the mind of another person by transferring information and feelings, and act as a suggestion (Fig. 1, III).

Depending on the level of interest, willpower and level of person's moral development, one can observe drastically different behavior ranging from the manifestation of the feeling of obligation and complete engagement to a relatively superficial, or even irresponsible, attitude towards performing the professional duties.

In case when the occurred interest directs the person's will to the performance of moral actions, it is accompanied by a strong stimulating impulse. In this case, the willpower is sufficient to mobilize the whole intellectual and physical potential in order to perform certain actions

If a person has a mindful and responsible attitude, he focuses his attention on the correct analysis of the external and internal conditions, regardless of his qualities, psychophysiological state, quality of professional training and current problems. His actions are based on responsibility and concern about people's lives, security of the machinery and preservation of Nature. In this case, the feeling of obligation and responsibility have a strong mobilizing effect and serve as a constant stimulation to overcome difficulties and limitations. Such behavior provides the highest security and effectiveness of the work process. 
If a working person's will is directed at fulfilling certain selfish actions, which are based on satisfying the personal needs (e.g., a wish to self-actualize, prove one's abilities, get in front of others, win, get a profit, etc.), initially, these actions are stimulated by the interest per se. The interest per se is a stimulus. However, such stimulus as the selfish interest is not related to highly moral feelings of obligation and responsibility, engagement, self-sacrifice, discipline, concern about the people and Nature. Such interest is aimed only at satisfying personal needs and usually disappears upon the failure to satisfy them. With such approach, a person would not work "from the heart", "for the idea", "for the wellbeing" of the company, the team, the society and Nature, and his actions would turn out to be inefficient and unsafe [6].

If the will is directed at satisfying low and immoral wishes and urges, the person's spiritual (moral) essence begins to fight his "unhealthy" interest and will that are invested in fulfilling the immoral idea. This is the frequently observed conflict between the higher and the lower human nature (between conscience and urge), the outcome of which primarily depends on the power of his morality, will and interest. If a person's will to fulfill a certain low urge is very strong, it can lead the occurring idea to specific actions independently from the resistance of the conscience. In such situation, a person's behavior can be cynically irresponsible, uncontrollable, dangerous and have unpredictable consequences.

If the interest and willpower are insufficient, a person would not finish the fulfillment of his idea or would renounce it, and the thought would be stored in the memory like many other unfulfilled thoughts.

It is necessary to point out the fact that the abovementioned conventional types of behavior are merely tendencies. In different conditions, the same person can act more or less virtuously, with more or less imagination and will, and experience different level of interest. Moreover, in the same situation, regardless of his moral beliefs, a person can act extraordinarily, therefore not meeting the expectations. The reason of such unpredictability is the variety of external conditions and person's states. Therefore, the information about a person's morality, willpower, predominant interests, professional and psychological training, qualities, skills, motivation and needs, when considered separately, cannot reveal the long-term tendencies of his behavior. The influence of all factors is always systematic, and in order to reveal the true inclines of a person, it is necessary to consider them in a unity and a dynamic interaction.

The results of the conducted situation modelling and observation show that there are three basic factors of the safety of human behavior that reflect the level of a person's spiritual and personal development and largely define the safety of his final decisions These factors are will, interest and virtue (Fig. 2). The basic factors of safety are the defining moments of safety of the whole human behavior; they are constant and robust. Therefore, it is almost impossible to affect them fast and effectively. The triad of "virtue - will - interest" is in unity and interaction: if there is no virtue, then will and interest lead to unsafe actions; if there is no will, then virtuous interests cannot be fulfilled; if there is no interest, then it is impossible implement the will for virtuous actions. If a person is brought up to manifest the will to moral and virtuous actions, regardless of the nature of the existing interests, he will direct his will to making highly moral and useful decisions in any situation. The abovementioned factors are essential factors that predefine further motivation of human behavior in all life situations. In turn, the factors that are currently considered to be the leading ones (cognitive skills, physical qualities, professional knowledge and skills and psychophysiological training) are in fact secondary (operational) factors.

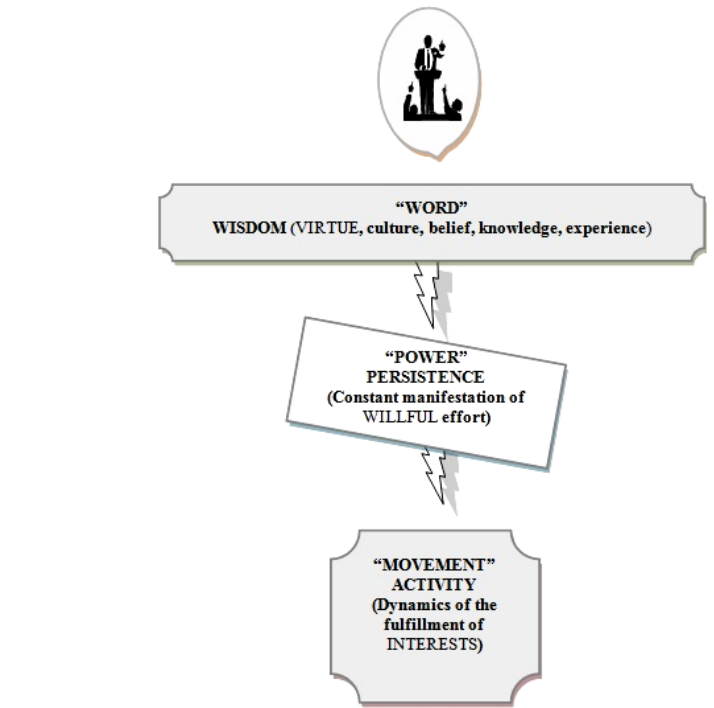

Fig. 2. Factors of safety and success of human behaviour (in the content of Christian tri-unity of the Universe structure)

Independently from this classification of the abovementioned factors, it is obvious that they have to be considered only as a system. Virtue, will and interest are the key factors only for the safety of human behavior, but they are insufficient to succeed. Only balanced development in terms of virtue and willpower and development of interests, together with professional, psychological and physical training, can become a good foundation for the prospective success of actions. In order to obtain high productiveness and safety of human actions, the virtue has to be deeply meaningful and has to turn into wisdom; the will has to be constant and has to lead to persistence, and the interest has to be maintained at the high level and has to lead to activity.

A person's virtue is a certain frame, within which free will and various and changing person's interests can manifest; therefore, virtue is the fundamental factor of the security of the human behavior. Moral (ethical) development (from Latin moralis - moral) is a process that helps a person from the childhood to actively perceive the world, as well as actively reproduce the conventional moral norms and values. Many researches come to conclusion that moral values of different cultures in the world are almost identical. Different societies might have different beliefs about what is good and bad, but these beliefs have the same universal "natural" (fundamental) meaning. It is possible to address all of the moral values that are currently known to the humankind in light of this meaning, and realize that all of them are shared both for evaluation of the observed natural phenomena, and the for evaluation of human thoughts, feelings and actions. All moral values follow the ethical meaning of the existing natural and, together with that, general human principles, such as principle of unity, principle of creation and destruction, principle of harmony, principles of information, hierarchy, successiveness, dynamics; free will, preclusiveness, stability, regulation, economy, etc. In such context, immoral human behavior is such behavior that contradicts the existing laws of nature, and moral behavior is the behavior that corresponds with them.

Furthermore, it is necessary to solve one other problem, namely, how is it possible to objectively evaluate what is moral and what is not, in the context of the description above. Currently, all human activity is evaluated according to the quantity and quality of the achieved result (manufactured product, service, action) and gain (loss) for the performer or the producer. Such evaluation of the achieved results contains the evaluation of the invested will and reflects the expressed interest, but this commonly used system fully lacks the most important aspect of evaluating human activity, that is the moral aspect. Such problem exists mostly because only a small number of currently known moral qualities can be objectively evaluated. Evaluation of the characteristics related to the 
moral qualities is very complicated, subjective and ultimately incorrect.

In order to solve the problem of the moral evaluation, the authors propose a new approach that consists in integrating the currently existing criteria of moral evaluation into the three global moral criteria: conformity to natural laws (representing a person's attitude towards nature); humanism (representing a person's attitude towards other people) and manifestation of obligation and responsibility (representing the power of a person's moral beliefs). Such approach focuses the moral evaluation on these three crucial aspects of human existence, significantly decreases the number of the used characteristics and simplifies the subsequent method of evaluation [6].

The only way to compensate for the inevitable subjectivity of the moral evaluation (a person is inevitably evaluated by another person) is to compare the expert evaluations with the social (collective) evaluation. This fact implies that the process of moral evaluation obeys one other (the fourth) criterion - collective (social) control - that represents the attitude of the society to a person.

The paradigm presented above implies diagnosing the quality of professional activity not in a way that is used now, i.e., according to such criteria as education, social status, age, professional experience, professionally relevant qualities, personal and psychophysiological skills (temperament, personality, qualities, skills and personality orientation). Such evaluation provides an answer to the question What can a person do? but does not answer the question How much can this person be trusted? A complete evaluation of a person's activity has to be conducted with consideration of its axiological characteristics, with consideration of not only the level of professionalism but also his "active life and professional position".

Based on the presented paradigm, the authors developed a method of axiological evaluation of professional activity of specialists and directors (regardless of the professional field and specialty), according to which the inspection is conducted either by single experts, or by an expert group during the education and work upon eight interrelated criteria: professionalism, attitude towards people attitude towards nature, responsibility, will, interest, psychophysiological qualities and skills, collective (social) evaluation.

Moreover, the evaluation on the criteria of professionalism and psychophysiological qualities and skills reflects the extent to which a person's behavior corresponds with the professional requirements. The evaluation on the criteria of attitude towards people, attitude towards nature and responsibility represent the level of trust towards a person, while the evaluation on the criteria of will and interest represent his attitude towards the performed work. All professional, personal, moral and ethical qualities and skills of a person are considered here as an integral result of expert and collective evaluation [7].

This method implies that specialists and directors can pass four types of evaluation that allow them to gain access to the work on each separate stage: planning and organization of professional activity, work in normal conditions, actions in extreme situations, certification for the successful conclusion of the year (complete evaluation) and access to a promotion.

It is reasonable to conduct the evaluation at the stage of planning and organization of professional activity (EPOPA) after the corresponding cycle of training. The evaluation gives the employee (the director) access to the evaluation of work in normal conditions The evaluation at the stage of work in normal conditions (EWNC) is conducted after the EPOPA and completion of the corresponding cycle of training in learning the responsibilities during the work in normal conditions. The evaluation gives the right to work in normal conditions and gives access to the evaluation of actions in extreme situations.

The evaluation of actions in extreme situations (EAES) can be conducted after the EPOPA, EWNC and the completion of a corresponding cycle of training in the extreme situations. The evaluation gives the right to act in the extreme situations and to participate in the complete annual evaluation.
The complete evaluation is conducted at the end of the year in order to make conclusions about the professional training. The complete evaluation also gives the right for promotion. In this context, it has to be conducted with consideration of the requirements from the new prospective work place and the new responsibilities, and it has to reveal the employee's potential abilities on the new job.

For each type of evaluation, the experts that conduct it can choose one of the following variations of evaluation (depending on the present goals):

1.Evaluation of knowledge and abilities: includes the evaluation of knowledge of the specialty, knowledge of the structure of the employed technological devices, knowledge of responsibilities in the separate schedules, knowledge of the regulating documents, knowledge of emergency evacuation equipment, norms of technical maintenance and use, rules, etc. It is conducted via examinations, testing and evaluation of separate sets of knowledge.

2.Evaluation of skills: includes the evaluation of practical actions during the simulation training, educational practice or real work conditions.

3.Comprehensive evaluation: includes an integral evaluation of knowledge, abilities and skills of a specialist (a director) in the conditions of a classroom, a simulation or a real work environment.

The proposed sequence of actions for conducting the evaluation allows making the following conclusions:

1.Before the evaluation, the director of the human resources department conducts a preparatory work. He/she develops the criteria and characteristics of the evaluation, prepares the necessary sheets for the evaluation of employees' activity, gives the instructions to the experts that will conduct the evaluation, establishes the schedule of the evaluation and prepares the necessary materials for the participants of the evaluation.

2. The evaluation in subdepartments is organized by their directors. If the evaluation concerns the directors of the subdepartments, it is organized by the directors of the organization.

3. The directors of the organization publish the normative documents about the evaluation procedure. These documents include the act, the list of evaluation committee members, the plan of evaluation, the evaluation method, instructions for formatting and storing the information, training program for the directors for the conduction of the evaluation.

4.Human resources department prepares the evaluation sheet, instructions for its completion and requirements for the evaluation conduction. All of this is prepared for each employee that is being evaluated.

5. The main evaluation document is the evaluation sheet that contains all relevant information about the evaluation.

6.The director or the specialist that is being evaluated has to fill in the evaluation sheet and describe the main work that has been done during the evaluated period of time.

7.The director conducts the evaluation of the employee's activity based on the description of the work completed in the evaluated period of time, and then interviews the employee.

8. The director and the evaluation committee go over the employee's evaluation materials.

The director is responsible for keeping the evaluation impartial As a result, the evaluation becomes the conclusion of the committee's work, and the basis of the decision about further perspectives of the employee. The final decision about the evaluation is the decision of the committee chairman together with the director of the subdepartment. Then, considering the evaluations and recommendations, a decision about the employee's further professional development is made.

The "method of axiological evaluation of professional activity of specialists and directors" can be used in any profession and specialty and be presented in a convenient format for programming and electronic data analysis. In such form, it is only one of the possible solutions of the problem of mathematical analysis of a large amount of subjective data. The method reflects the most 
general principles and statements that constitute the basis of the presented approach. Depending of the professional specifics, it allows changing the number and content of the proposed characteristics and can include additional mathematical modules for calculating the given parameters.

\section{Conclusion}

The presented results of the study that addressed the logic of human behavior development lead to the following conclusions:

- There are powerful robust behavioral characteristics that do not depend on the temporary state of a person, specific conditions and duration of work. In normal and extreme conditions, the leading factors that predefine the logic of person's behavior are virtue, will and interest.

- The revealed system of factors and the related system of criteria provides an actual opportunity to exit the maze of evaluation of a large number of psychophysiological characteristics that are related to sensory, perceptive, psychomotor, memory, attentional, thinking and imaginative qualities of an individual, the nervous system and cognitive style, and comprehend the general patterns of the development of human behavior regardless of the conditions.

- The conclusions of the study radically change the existing understanding of the direction of effort in the field of education, science and professional activity. Currently, this effort is directed primarily at producing highly trained specialists with welldeveloped qualities and skills but without the understanding of the laws of Nature and respect towards it and the people. Such approach leads only to a weak, temporary and illusory effect of the increased quality and safety of the performed activity. The attempts to optimize the secondary factors (professional skills, qualities and abilities) and neglect the key factors that affect the quality and safety of work (interest-will-virtue) are the fundamental errors and the reasons of rather low effectiveness of the modern educational, scientific and professional approaches.

In order to solve the problem of improving the human behavior, it is necessary to employ certain resources, such as intellectual, managerial, organizational, administrative.... and least of all, financial ones. However, all of the necessary resources can be found only when the moral qualities will be truly demanded by the society and only when there will be the necessary comprehension that any unbalanced human development inevitably leads to the circle of ineffectiveness and unsafety.

\section{References}

[1] Druker PF (1989), The New Realities. NY, USA: Harpercollins.

[2] Gagarina OD (2009), Chelovecheskij faktor v kontekste koncepcii chelovecheskogo potenciala. Nauchnyj vestnik MGTU GA. Seriya Istoriya, filosofiya, sociologiya, 142 , pp. 76-80.

[3] Marinov M \& Malygina E (2013), Rol' chelovecheskogo faktora $v$ probleme transportnoj bezopasnosti. Problemy upravlenija riskami $v$ tehnosfere 2(26), 19-26.

[4] Taha MH, Bulycheva OS, Sadaka DY (2014), Rol' chelovecheskogo faktora v tekhnogennoj i social'noj bezopasnosti, Uspekhi sovremennogo estestvoznaniya 6, 94-94.

[5] Sinickaya NY (2016), Razvitie teorii chelovecheskogo kapitala: nauchnyj obzor. Nauchnoe obozrenie. Ekonomicheskie nauki 2, $182-190$

[6] Marinov M \& Starichenkov A (2017), The concept of software developments for professional value diagnostics activity of marine professionals. Marine Intellectual Technologies Scientific Journal $2(36), 87-89$

[7] Skorokhodov D, Lubenov M \& Komashinskij V (2017), Method of diagnosis of the professional activities of staff transport systems, taking into account its axiological characteristics. Marine Intellectual Technologies Scientific Journal 1(35), 73-80. 